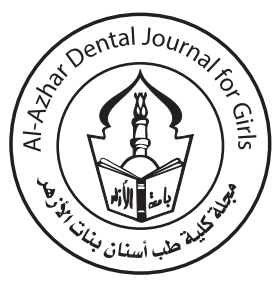

\title{
Evaluation of Surface Characteristics of Ti- Implant Coated with Nano-Ceramic and Chitosan after Sterilization by Gamma Irradiation
}

\author{
Marwa B. Seif ${ }^{1 *}$, Inas T. Motawea ${ }^{2}$, Eatemad A. Shoreibah ${ }^{3}$, Eman M. F. El-Maghraby ${ }^{4}$, Heba A. Shalaby ${ }^{5}$
}

Codex : 04/22.01

azhardentj@azhar.edu.eg

http://adjg.journals.ekb.eg

DOI: $10.21608 /$ adjg.2021.50250.1322

Restorative Dentistry

(Removable Prosthodontics, Fixed

Prosthodontics, Endodontics, Dental Biomaterials, Operative Dentistry)

\section{KEYWORDS}

Titanium, Magnesium oxide,

Chitosan, Gamma radiation

\begin{abstract}
Purpose: This study aimed to monitor the surface characteristics of commercially available titanium implants coated with chitosan and magnesium oxide after sterilization by two different doses of gamma radiation as well as optimizing the most suitable dose of sterilization. Materials and Methods: A total number of 120 titanium alloy discs divided into six groups $(\mathrm{n}=20)$ were used. Group 1A, included implants coated with magnesium oxide $(\mathrm{MgO})$, Group $1 \mathrm{~B}$, implants coated with $\mathrm{MgO}$ and sterilized with $20 \mathrm{KGy}$, Group 1C,implants coated with $\mathrm{MgO}$ and sterilized with 25 KGy, Group 2A, implants coated with chitosan, Group 2B, implants coated with chitosan and sterilized with $20 \mathrm{KGy}$, Group 2C, implants coated with chitosan and sterilized with $25 \mathrm{KGy}$. Characterization of the different prepared dental implant surfaces was done by X-ray diffraction (XRD) and Fourier Transform Infra-Red Spectroscopy (FTIR). Topographical identification was done using Environmental scanning electron microscope (ESEM). Results: No detected changes occurred in XRD graphs after sterilization in all groups, The FTIR graph of magnesium oxide groups showed no changes while there were decrease in the intensity of all peaks in chitosan groups after sterilization. The results of surface roughness revealed that the highest mean surface roughness $(\mu \mathrm{m})$ was recorded for chitosan after $25 \mathrm{KGy}(189.2 \pm 7.8 \mu \mathrm{m})$, and the least mean surface roughness was recorded for chitosan before sterilization $(135.2 \pm 12 \mu \mathrm{m})$. Conclusions: Titanium implants coated with Magnesium Oxide can be sterilized with either doses of gamma radiation 20 and $25 \mathrm{KGy}$ while titanium implants coated with Chitosan can be sterilized with $20 \mathrm{KGy}$, whereas the $25 \mathrm{KGy}$ denaturated the chitosan coating.
\end{abstract}

* $\quad$ Paper extracted from Doctor Thesis titled "Evaluation of Surface Characteristics of Ti- Implant Coated with Nano-Ceramic and Chitosan after Sterilization by Gamma Irradiation".

1. Assistant Lecturer, Health Radiation Research Department, National Centre for Radiation Research and Technology (NCRRT), Egyptian Atomic Energy Authority, Cairo ,Egypt.

2. Professor of Dental Biomaterials and Dean of Faculty of Dental Medicine for Girls, Al-Azhar University, Cairo, Egypt.

3. Professor of Oral Medicine \& Periodontology, Faculty of Dental Medicine for Girls, Al-Azhar University, Cairo, Egypt.

4. Professor, Health Radiation Research Department, National Centre for Radiation Research and Technology (NCRRT), Egyptian Atomic Energy Authority, Cairo, Egypt.

5. Assistant Professor, Dental Biomaterial Department, Faculty of Dentistry, Alfyoum University, Egypt And Faculty of Dentistry, Nahda University, Beni Sweif , Egypt .

*Corresponding author email: marwa.bahaa1@gmail.com 


\section{INTRODUCTION}

Titanium (Ti) dental implant has been widely used because of the biocompatibility of its thin titanium oxide layer and its excellent corrosion resistance. However, its low bioactivity causes poor adhesion to the surrounding biological tissues causing implant loosening and failure ${ }^{(1)}$.

Many surface modification strategies have been used to enhance osseointegration of dental implants, either by coating to improve the osseoconductivity of dental implants as magnesium oxide $(\mathrm{MgO})$ or by adding antibacterial properties to dental implants surfaces as chitosan which is a natural polymer derived from crustaceans ${ }^{(2)}$.

The necessity of sterilization of any biomaterial device before implanting in the body makes the sterilization process considered as the last step of the surface modification. There are many different sterilization techniques, including steam autoclaving, dry heat, radiation, ethylene oxide, ultraviolet radiation and formaldehyde sterilization ${ }^{(3)}$.

In recent years, ionizing radiation (gammairradiation) has gained widespread importance in sterilization because it has high penetration power, suitable for heat-sensitive materials, assures homogeneous sterilization and is useful for packaged products $^{(4)}$.

Investigation of the effect of irradiation on the chemical and physical properties of polymers was necessary because irradiation of polymers may cause crosslinking, and main-chain scission depending on the state of the polymer and the nature of irradiation ${ }^{(5)}$. Dry heat or steam sterilization of chitosan require heating at high temperatures reducing the efficiency of chitosan. Ethylene oxide sterilization leave toxic residues which compromise the biocompatibility of chitosan while gamma irradiation may be a suitable method as the biocompatibility of chitosan is not affected ${ }^{(6)}$.
The effect of gamma irradiation on the features of pure magnesium oxide $\mathrm{MgO}$, titanium oxide $\mathrm{TiO}_{2}$ and $\mathrm{MgO}-\mathrm{TiO}_{2}$ binary oxides have been investigated using Fourier Transform Infrared spectroscopy showing slight shift in the transmittance spectra after irradiation ${ }^{(7)}$. The effect of gamma-rays on structural, optical and photocatalytic properties of $\mathrm{MgO}$ nanoparticles under controlled atmospheres showed that gamma radiation did not change the crystallinity of $\mathrm{MgO}$ nanostructures ${ }^{(8)}$.

The effect of common sterilization treatments on the degradation of chitosan-based materials were compared with four sterilization methods: gamma irradiation, beta irradiation, exposure to ethylene oxide and saturated water steam sterilization (autoclaving). Exposure to gamma or beta irradiation was shown to induce prominent degradation of chitosan, regardless of its physical state. The chemical structure of chitosan flakes was preserved after ethylene oxide sterilization, but this technique has a limited use for materials in the dry state. Saturated water steam sterilization of chitosan solutions led to notable depolymerization ${ }^{(9)}$.

In the present study the surface characteristics of commercially available titanium implants coated with chitosan and magnesium oxide layer were evaluated after sterilization with two different doses of gamma radiation to optimize the most suitable dose of sterilization.

\section{MATERIAL AND METHODS}

\section{Specimens' preparation:}

A total number of 120 Ti-6Al-4V (Titaniumaluminum-vanadium alloy $\mathrm{Ti}$ with $6 \% \mathrm{Al}$ and $4 \%$ V) (Pol. Ind. "El Segre”, C/ Enginyer Míes, 705 A, Lleida, Spain) discs were coated by $\mathrm{MgO}$ and chitosan. The dimensions of the disc were $6 \mathrm{~mm}$ in diameter and $2 \mathrm{~mm}$ in thickness. The discs were then divided into 6 groups ( $\mathrm{n}=20$ discs). 


\section{Specimens' grouping:}

Group 1A; Ti - 6\% Al- 4\% V alloy discs coated by $\mathrm{MgO}$ ceramics ${ }^{(10)}$.

Group 1B; $\mathrm{Ti}-6 \% \mathrm{Al}-4 \% \mathrm{~V}$ alloy discs coated by $\mathrm{MgO}$ and subjected to sterilization dose $20 \mathrm{KGy}$.

Group 1C; $\mathrm{Ti}-6 \% \mathrm{Al}-4 \% \mathrm{~V}$ alloy discs coated by $\mathrm{MgO}$ and subjected to sterilization dose $25 \mathrm{KGy}$.

Group 2A; Ti - 6\% Al- 4\% V alloy discs coated by chitosan ${ }^{(11)}$.

Group 2B; Ti - 6\% Al- 4\% V alloy discs coated by chitosan and subjected to sterilization dose $20 \mathrm{KGy}$.

Group 2C; Ti - 6\% Al- 4\% V alloy discs coated by chitosan and subjected to sterilization dose $25 \mathrm{KGy}$.

Irradiated groups were transferred to Indian cobalt-60 as shown in (Fig.1) (National Centre for Radiation Research and Technology (NCRRT), Cairo, Egypt) to be subjected to gamma radiation. The discs were installed in the gamma cell chamber. Irradiation chamber dimensions were: Diameter $16 \mathrm{~cm}$, Height $20 \mathrm{~cm}$. The discs were positioned with the long axis perpendicular to the floor of the chamber and parallel to the cobalt source. The irradiation area was defined allowing the whole disc to receive the same dose. The irradiation was done in vacuum. The dose was in the range of $1.0431 \mathrm{KGy} /$ hour at the time of experiment. Group $1 \mathrm{~B}$ and $2 \mathrm{~B}$ were subjected to $20 \mathrm{KGy}$ while group $1 \mathrm{C}$ and $2 \mathrm{C}$ were subjected to $25 \mathrm{KGy}$.

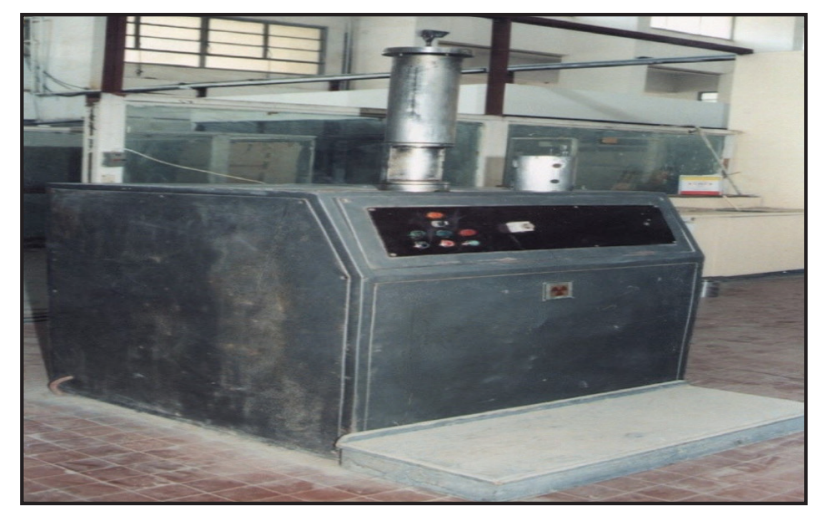

Figure (1) Indian gamma cell

\section{Chemical Surface Changes:}

Surface chemical phases changes of different investigated groups were examined by using X-ray diffraction (XRD) (PAN analytical, X'Pert Pro, Holand.), and Fourier Transform Infra-Red Spectroscopy (FTIR) (FT/6300 type A. Jasco, Japan).

XRD was performed in order to identify the constituents' phases of the discs' surfaces using thin film X-Ray diffractometer with a copper target $(\mathrm{Cu}$ $\mathrm{k} \alpha=1.54060$ ) and Nickel filter. Omega angle of X-ray beam had been controlled according to the analyzed film coating.

The infra-red spectra of the coating were obtained in reflection percentage at 400-4000 with a resolution of $8 \mathrm{~cm}^{-1}$ in reflectance mode. The wavelength was used to analyze the surface chemical composition qualitatively. The peaks of the desired functional groups were observed and compared to the data from reference publications.

\section{Surface Topography}

The average surface roughness of the irradiated and non-radiated groups was monitored by using environmental scanning electron microscope (ESEM) (Quanta 200, FEI, multinational gathered at Netherlands). The captured image for each sample with 1000X magnification was converted to a three dimensional image. Using a computer and advanced texture analysis software. The average surface roughness were statistically analyzed.

\section{RESULTS}

\section{Results of XRD analysis}

XRD pattern of $\mathrm{MgO}$ before gamma irradiation Group 1A (Fig. 2) was recorded on an X-ray diffractometer at room temperature. The peak values were compared with International Centre for Diffraction Data (ICDD) card number 03065-9622 and 00-007-0239 corresponding to $\mathrm{Ti}$ and $\mathrm{Mg}(\mathrm{OH})_{2}$ respectively. The maximum peak intensity $100 \%$ for $\mathrm{Mg}(\mathrm{OH})_{2}$ was captured at $2 \theta=$ 
40.4905, $\mathrm{d}=2.22789 \mathrm{in}$ addition to $2 \theta=38.7154,2 \theta$ $=53.2830,2 \theta=63.2559$ and $\mathrm{d}=2.32585, \mathrm{~d}=1.71928$, $\mathrm{d}=1.47013$ respectively. Whereas, the hexagonal Ti peaks was showed at $2 \theta=35.3956, \mathrm{~d}=2.53601$. Groups 1B (Fig. 3) and 1C (Fig. 4) after sterilization revealed the same surface chemical structure with no changes.

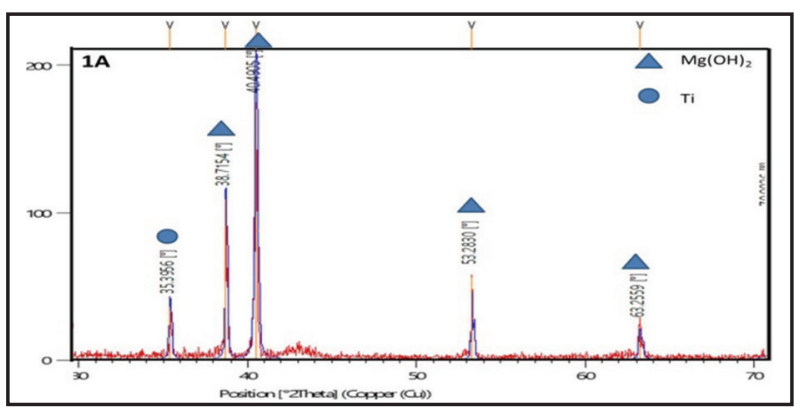

Figure (2) XRD peaks of Group 1A

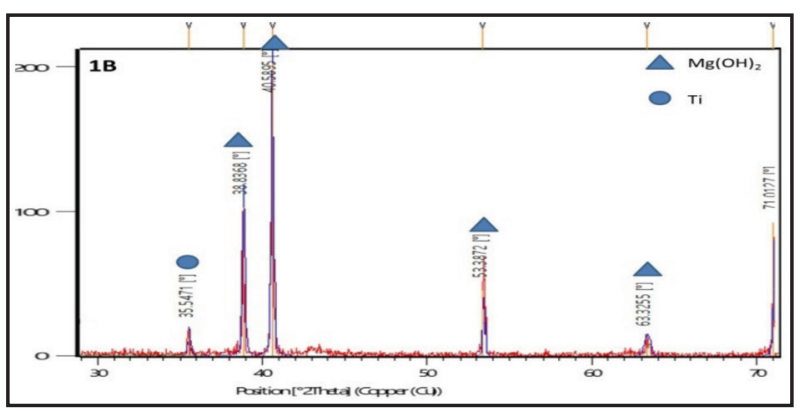

Figure (3) XRD peaks of Group 1B

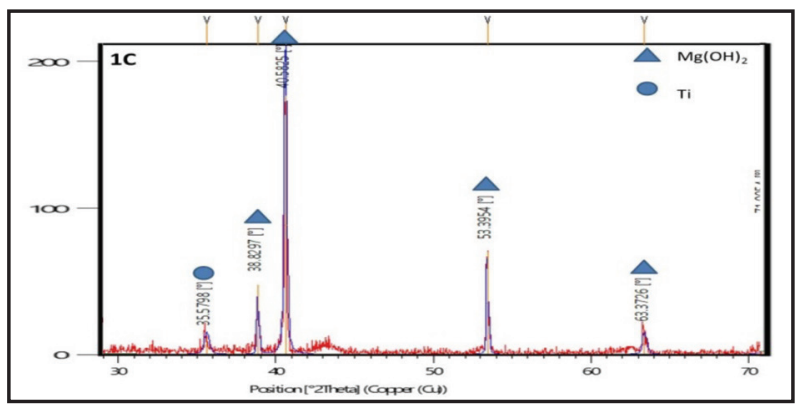

Figure (4) XRD peaks of Group 1C

XRD pattern of chitosan before gamma irradiation Group 2A (Fig. 5) was recorded on a $\mathrm{X}$-ray diffractometer at room temperature. The peak values were compared with International Centre for Diffraction Data (ICDD) card number 44-1294, 71-0574, and 81-1667 corresponding to $\mathrm{Ti}, \mathrm{Ti}_{4} \mathrm{O}_{7}$, and $\mathrm{Al}_{2} \mathrm{O}_{3}$ respectively. The maximum peak intensity $100 \%$ was found at $2 \theta=40.5752$, $\mathrm{d}=2.22343$, for titanium phase, while $\mathrm{Al}_{2} \mathrm{O}_{3}$, was captured at $2 \theta=35.4975, \mathrm{~d}=2.52896$. Whereas $\mathrm{Ti}_{4} \mathrm{O}_{7}$ was captured at $2 \theta=53.4145, \mathrm{~d}=1.71536$. On the other hand chitosan coated layer cannot be observed on the implant surface by XRD. Groups 2B (Fig. 6) and $2 \mathrm{C}$ (Fig. 7) after sterilization revealed no surface chemical changes in XRD pattern.

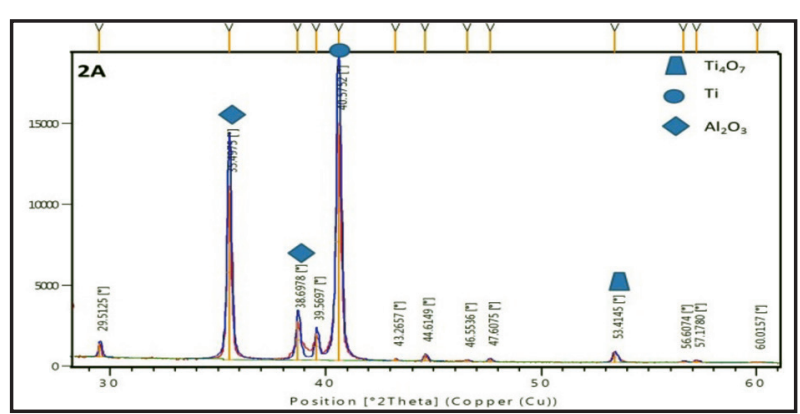

Figure (5) XRD peaks of Group 2A

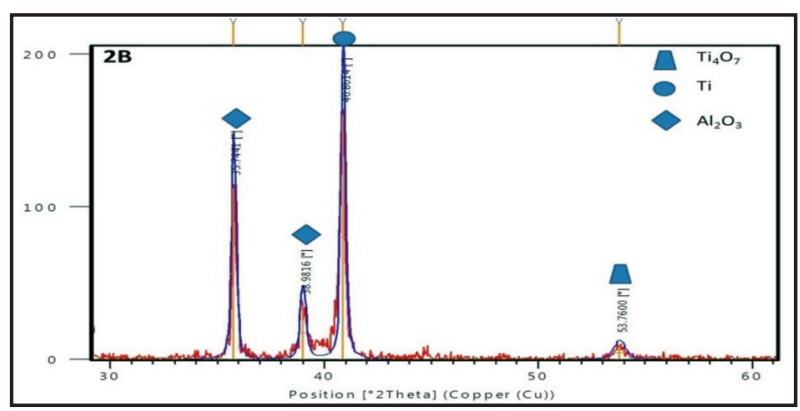

Figure (6) XRD peaks of Group 2B

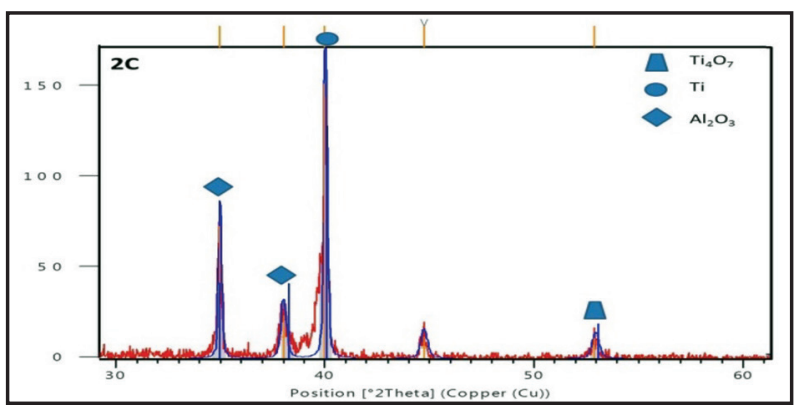

Figure (7) XRD peaks of Group 2C

\section{Results of Fourier Transform Infrared (FTIR):}

The FTIR spectra of Group 1A are shown in (Fig. 8). The spectra revealed the presence of sharp peaks at $688 \mathrm{~cm}^{-1}$ which is due to the $\mathrm{Mg}-\mathrm{O}$ bands The stretching vibration band captured at $1526 \mathrm{~cm}^{-1}$ 
is characteristic peak corresponding to the $\mathrm{O}-\mathrm{H}$ in-plane bending for $\mathrm{Mg}(\mathrm{OH})_{2}$. The peak at 1695 $\mathrm{cm}^{-1}$ indicates the bent vibration of $\mathrm{N}-\mathrm{H}$. There is a possibility that these bands at $3614 \mathrm{~cm}^{-1}$ can also be attributed to $\mathrm{O}-\mathrm{H}$ vibration in the absorbed water on the sample surface. The presence of $\mathrm{Mg}-\mathrm{O}$ bands was observed at around $526 \mathrm{~cm}^{-1}$. The FTIR spectra of Groups 1B and 1C are shown in (Fig. 8). The spectra revealed no changes in bands or their intensities after sterilization.

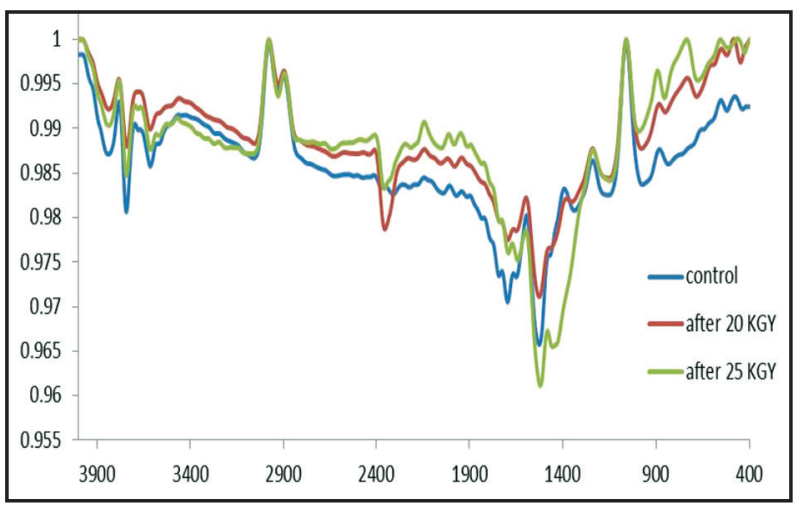

Figure (8) FTIR spectra of Groups 1A,1B,1C.

The FTIR spectra of Group 2A are shown in (Fig.9). The spectrum revealed the broad band of $\mathrm{H}-\mathrm{O}-\mathrm{H}$ group at $3286 \mathrm{~cm}^{-1}$. More absorbance spectra bands for $\mathrm{C}-\mathrm{H}$ stretching vibrations were captured at $2929 \mathrm{~cm}^{-1}$. The amide I represented by carbonyl bonds stretching vibrations $(\mathrm{C}=\mathrm{O})$ group was observed at $1641 \mathrm{~cm}^{-1}$. The amide II $(\mathrm{N}-\mathrm{H}$ stretching) was detected at $1545 \mathrm{~cm}^{-1}$. Stretching vibration of $\mathrm{C}=\mathrm{C}$ at $1406 \mathrm{~cm}^{-1}$. Asymmetric stretching vibration of the $\mathrm{C}-\mathrm{O}-\mathrm{C}$ bridge group was detected at $1150 \mathrm{~cm}^{-1}$. Symmetric stretching vibration of the C-O-C bridge at $1023 \mathrm{~cm}^{-1}$.

The FTIR spectra of Group 2B are shown in Fig.9. The spectral bands showed some bands that were right shifted and others left shifted. The left shifted spectral bands were; C-H stretching band shifted from $2929 \mathrm{~cm}^{-1}$ to $2941 \mathrm{~cm}^{-1}$ and $\mathrm{C}=\mathrm{O}$ group shifted from $1641 \mathrm{~cm}^{-1}$ to $1648 \mathrm{~cm}^{-1}, \mathrm{C}=\mathrm{C}$ band shifted from $1406 \mathrm{~cm}^{-1}$ to $1437 \mathrm{~cm}^{-1}$. Whereas, the right shifted bands were seen at $\mathrm{H}-\mathrm{O}-\mathrm{H}$ band shifted from $3286 \mathrm{~cm}^{-1}$ to $3273 \mathrm{~cm}^{-1}$, C-O-C bridge shifted from $1150 \mathrm{~cm}^{-1}$ to $1107 \mathrm{~cm}^{-1}$ and $\mathrm{C}-\mathrm{O}-\mathrm{C}$ bridge from $1023 \mathrm{~cm}^{-1}$ to $1011 \mathrm{~cm}^{-1}$. Moreover, there was a slight decrease in the intensity of all peaks.

The FTIR spectra of Group 2C are shown in (Fig.9). The spectrum band of $\mathrm{H}-\mathrm{O}-\mathrm{H}$ was disappeared. The right shift was observed at $\mathrm{C}-\mathrm{H}$ band moved from $2929 \mathrm{~cm}^{-1}$ to $2855 \mathrm{~cm}^{-1}$, and $\mathrm{C}=\mathrm{C}$ from $1406 \mathrm{~cm}^{-1}$ to $1401 \mathrm{~cm}^{-1}$. Whereas, the left shift was captured at $\mathrm{C}-\mathrm{O}-\mathrm{C}$ from $1023 \mathrm{~cm}^{-1}$ shifted to $1064 \mathrm{~cm}^{-1}$, and at $(\mathrm{C}=\mathrm{O})$ from $1641 \mathrm{~cm}^{-1}$ to 1651 $\mathrm{cm}^{-1}$., Severe general decrease in the intensity of all peaks was also observed.

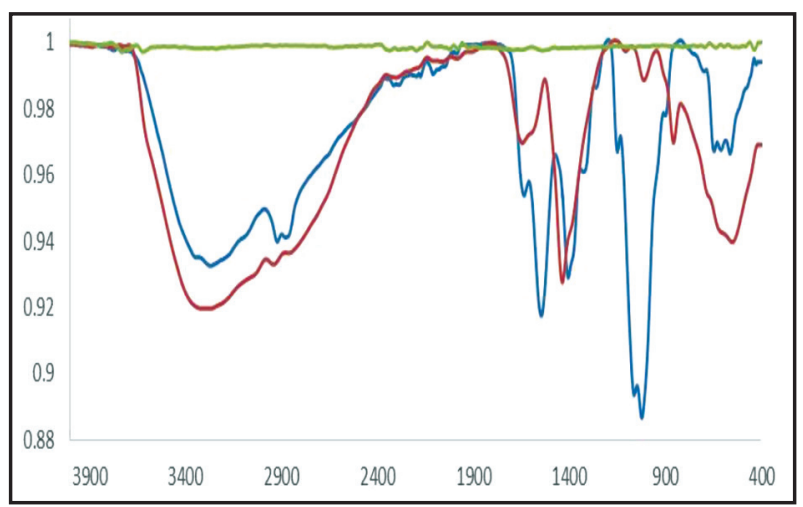

Figure (9) FTIR spectra of Groups 2A,2B,2C.

\section{Surface Roughness Measurement (Ra):}

Table 1 and Fig. 10 show the mean and standard deviation (SD) of surface roughness (Ra) in $\mu \mathrm{m}$ of all groups. The highest mean surface roughness $(\mu \mathrm{m})$ was recorded for Group 2C (chitosan after 25 KGy) $(189.2 \pm 7.8 \mu \mathrm{m})$ and the least mean surface roughness was recorded for Group 2A (chitosan before ) $(135.2 \pm 12 \mu \mathrm{m})$.Regarding gamma radiation sterilization there was a non-significant decrease in $\mathrm{MgO}$ after sterilization while there was a significant increase in chitosan after sterilization. Whereas, Group 2 (chitosan) recorded significant increase in (Ra) as the highest value was $(189.2 \pm 7.8 \mu \mathrm{m})$ for Group 2C (chitosan after $25 \mathrm{KGy}$ ). 
Table (1) Average surface roughness (Ra $\mu \mathrm{m})$ of all groups

\begin{tabular}{ccccc}
\hline & Before irradiation & After 20 KGy & After 25 KGy & p-value \\
\hline MgO & $186.9 \pm 14.2$ & $177.4 \pm 14.4$ & $175.5 \pm 11.7$ & 0.195 NS \\
\hline Chitosan & $135.2 \pm 12$ & $141 \pm 11$ & $189.2 \pm 7.8$ & $<0.001^{*}$ \\
\hline
\end{tabular}

NS: non-significan *:significant

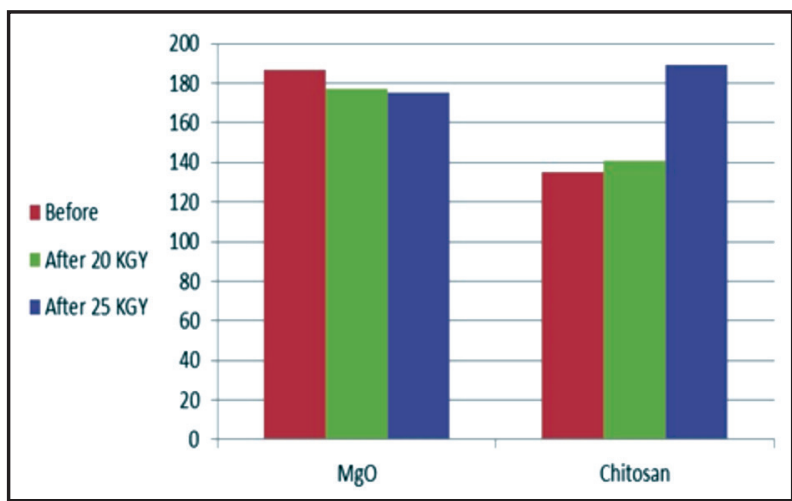

Figure (10) Histogram showing average surface roughness (Ra $\mu \mathrm{m}$ ) of all groups

\section{DISCUSSION}

Implants, as surgical components that have intimate contact with bone, need to be properly sterilized prior to the implantation or during the storage. Sterilization is considered as the final finishing procedure after the manufacturing process, because it may affect the implant surface and its modification, for enhancing rapid osseointegration of dental implants, many innovative coating techniques have been developed depending on precipitation of proteins and growth factors. The physico-chemical properties of implant surface that was coated by protein might be changed after sterilization which may have a negative clinical impact leading to implant failure ${ }^{(12)}$.

Hence, the chemical analysis for surface changes after sterilization is mandatory process for determining the effectiveness of surface bioactivity of coated implant.
Several sterilization methods have been established over past decades especially to allow protein surface sterilization. These methods include steam processing/autoclaving, treatment with ethylene oxide, plasma sterilization, as well as irradiation with electron beams (beta irradiation), gamma-radiation or X-rays. The sterilization method has to be chosen according to materials used for implants, because sterilization itself can be inappropriate, ineffective or even destructive ${ }^{(13)}$.

In the present study gamma irradiation was chosen. Gamma irradiation from a cobalt-60 (Co60 ) source is lethal to all forms of microorganisms and it has the advantage of sterilizing without high temperature and pressure, chemicals or gases ${ }^{(12)}$. There are many doses for sterilization. There is good justification for considering the most suitable radiation dose between 5 and $25 \mathrm{kGy}$ due to having the potential to reduce the deleterious effects of radiation on materials properties ${ }^{(14)}$.

Gamma irradiation sterilization is performed by exposing the product to a radiation source, typically Cobalt 60 isotope, which decomposes into Nickel 60 isotope, firing off gamma rays in the process. These gamma rays can penetrate through the entire product, deactivating whatever microorganisms may be present ${ }^{(15)}$.

$$
{ }_{27}^{60} \mathrm{Co} \rightarrow{ }_{28}^{60} \mathrm{Ni}+\mathrm{e}^{-1}+\text { gamma rays. }
$$

Compositional analysis was done by several machines, in this study, XRD was used as it provides information about the crystal structure of the compositional elements as well as the crystal size of the formed structure. Hence, XRD was chosen 
for characterization of sterilized surface coated implants in combination with FTIR to identify the functional groups of the organic components over the surface before and after gamma sterilization ${ }^{(16)}$.

Topographical analysis of the surface coat is considered a critical issue in the evaluation of dental implants, also surface roughness is considered to be the most important parameter. Environmental scanning electron microscope was used in this study as it is an excellent method to determine the biocompatibility of orthopedic and orthodontic biomaterials, due to the opportunity to observe the surface roughness, as well as the homogeneity of surface coatings. The minimal sample preparation represents the main advantages of ESEM. Indeed, the dehydration and metallization steps can be avoided in ESEM mode ${ }^{(17)}$.

X-ray diffraction pattern of all groups revealed no change in crystalline chemical structure of implant surfaces before and after $\gamma$-irradiation as no change occurs in their crystalline phase. $\mathrm{MgO}$ is strong refractory material so that the kinetic energy in the sterilization process is not sufficient to break the chemical bonds to neighboring atoms. This was in agreement with previous studies ${ }^{(3,18)}$ which investigated the structure properties and mass attenuation coefficient of $\mathrm{MgO}$ nanoparticles before and after gamma irradiation. Moreover, these findings are also in consistent with other study ${ }^{(19)}$ that showed the influence of different doses of $\gamma$-irradiation (100 Gy, 1 kGy, 10 kGy and 20 kGy from 60Co source) on the optical and structural properties of magnesium oxide $(\mathrm{MgO})$ nanoparticles.

The FTIR of $\gamma$-irradiated magnesium oxide groups are similar to the non-irradiated group. This might be attributed to the low dose of radiation. As many researchers reported that the 20 and 25 KGy gamma irradiation have a weak effect on the crystal structure and morphology of $\mathrm{MgO}$. While, the higher doses (i.e. higher than $75 \mathrm{kGy}$ ) caused irreversible damage to the oxide lattice which would negatively affect the properties of the binary system and therefore limit its usage ${ }^{(7)}$.

Surface topography of $\mathrm{MgO}$ coated implants Group 1A showed non-significant difference in average roughness $(\mathrm{Ra})$ with irradiated Groups $1 \mathrm{~B}$ and $1 \mathrm{C}$, as there is no change in chemical structure, this assured the above explanation and in agreement with a previous study ${ }^{(20)}$ which revealed that Co60 $\gamma$ ray radiation sterilization may be the most appropriate sterilization process for biomedical magnesium alloys.

On other hand, the FTIR results of Chitosan coating (Group 2A) showed right and left deviation in different bands after subjecting to irradiation, in spite of no change in XRD pattern. Chitosan surface coating has an amorphous structure, so couldn't be detected in XRD but can be monitored by FTIR ${ }^{(21)}$. Group 2B that was subjected to $20 \mathrm{KGy}$ revealed right shift in certain functional groups and decrease in intensity as in $\mathrm{H}-\mathrm{O}-\mathrm{H}$ band and $\mathrm{C}-\mathrm{O}-\mathrm{C}$ bridge. This might be due to starting the crosslinking of polymer chain. It is well known that the main effect of the interactions of gamma rays with polymers is the formation of free radicals, whose further evolution can cause chain scission, chain branching or crosslinking ${ }^{(22)}$.

Minimal changes in the FTIR of Group 2B that was subjected to $20 \mathrm{KGy}$ may be attributed to the fact that irradiation effects are dose dependent, a higher irradiation dose lead to stronger changes. In general, $\gamma$-irradiation should have the highest capability to cleave the polymer chains because of its higher photon energy compared to $\beta$ - and X-ray irradiation. High energy radiation does not only sterilize a medical device made from polymers, but can also result in a scission of the polymer chains. Since these effects were stronger at higher irradiation doses, a low dose should be chosen for medical devices sterilization $^{(13)}$.

A combination between scission and crosslinking reactions has been noticed in some irradiated 
polymers with increased irradiation dose, this might be explained by the further loss of $\mathrm{H}-\mathrm{O}-\mathrm{H}$ band on increasing the dose of irradiation in Group 2C. This could also explain the results of surface topography as surface roughness of that group was significantly increased to $189.2 \mu \mathrm{m}$. Moreover, It was reported that the increase in roughness is usually accompanied by increase in radiation dose ${ }^{(23)}$.

Polymers are generally classified as predominantly undergoing degradation and crosslinking when exposed to ionizing radiation. Natural polymers like cellulose (carboxy methyl cellulose) and other marine based polysaccharides (chitin/chitosan, alginates, and carrageenan) are predominantly chain-scissioning polymers ${ }^{(22)}$.

The results of the present study revealed general decrease in the intensity of all peaks of FTIR in Group $2 \mathrm{C}$. This could be attributed to the vibrations induced by the ionizing radiation ${ }^{(8)}$. Irradiation of polymer can produce radicals in the polymer chain by hydrogen abstraction and chain scission at any bond within the polymer chain ${ }^{(24)}$.

\section{CONCLUSIONS}

Within the limitations of the present study, it was concluded that:

1. Titanium implant coated with magnesium oxide can be sterilized with either doses of gamma radiation 20 and $25 \mathrm{KGy}$ without affecting the surface chemistry.

2. Titanium implant coated with chitosan can be sterilized with $20 \mathrm{KGy}$ whereas the $25 \mathrm{KGy}$ denaturated the chitosan coating.

\section{CONFLICT OF INTEREST}

None declared.

\section{FUNDING}

No funding was received for this study.

\section{REFERENCES}

1. John W. A review on Titanium Alloys for Dental Implants. Prosthesis 2020; 2 :100-16.

2. In-Sung L. Modifications of Dental Implant Surfaces at the Micro- and Nano-Level for Enhanced Osseointegration. Mater.2020; 13: 89-105.

3. Aifang H, James K, Zhuofan C, Yu Z, Jukka P. Effects of different sterilization methods on surface characteristics and biofilm formation on zirconia. Dent Mater. 2018; 34: 272-81.

4. Saleh M, Ebraheem S. ESR Studies on Characteristic Physio-chemical Effects of Some Irradiated Antibiotics Egypt. J. Rad. Sci. Applic. 2018 ; 31:137 - 42 .

5. Abdel Moez A, Aly SS, Elshaer YH. Effect of gamma radiation on low density polyethylene (LDPE) films: optical, dielectric and FTIR studies. Spectrochim Acta A. 2012; 93:203-7.

6. Abdel Ghaffar A, Ali H, Nasef SH, Heba A. Effect of Gamma Radiation on the Properties of Crosslinked Chitosan Nano-composite Film. J. Polym. Environ.2018; 26:3226-36.

7. El-Sayed S, Amer M, Meaz T, Deghiedy N, El-Shershaby $\mathrm{H}$. Investigational analysis on irradiated $\mathrm{MgO}-\mathrm{TiO} 2$ binary oxide. Mater. Res. 2018; $5: 1-11$.

8. Bourezgui A, Kacem I, Daoudi M, Ahmed F. Influence of Gamma-Irradiation on Structural, Optical and Photocatalytic Performance of $\mathrm{TiO} 2$ Nanoparticles Under Controlled Atmospheres. J. Electron. Mater. 2020 ;49: 1904-14.

9. San Juan A, Montembault A, Gillet D, Say J, Rouif S, Bouet $\mathrm{T}$ et al. Degradation of chitosan-based materials after different sterilization treatments. IOP Conf. Ser. Mater. Sci. Eng. $2012 ; 31: 1-5$.

10. Abdelrahman A M . Bioactivity of a Novel NanoCeramic Coating of Titanium Alloy Implant Surfaces and Its Effect on Osseointegration..PHD thesis. Ain Shams University 2017.

11. Gamal D A, Hashem A M, Shoeib M A, Shalaby H A, Abdelraouf R M. Electrode-deposition of biological active chitosan/composite coating on titanium implant. Egypt Dent J. 2017; 63:1417-28

12. Shi X, Xu L, Violin KB, Lu S. Improved osseointegration of long-term stored SLA implant by hydrothermal sterilization. J Mech Behav Biomed Mater. 2016; 53:312-9.

13. Dominik d, Anna L, Birgit G, Henning M. Impact of sterilization by electron beam, gamma radiation and $\mathrm{X}$ rays on 
electrospun poly-( $\varepsilon$-caprolactone) fiber mats. J Mater Sci Mater Med. $2019 ;$ 30:42-55.

14. Semin K, Jin-Oh J, Sanghun L, Jong-Seok P, Hui-Jeong G, Sung I et al. Effective gamma-ray sterilization and characterization of conductive polypyrrole biomaterials. Sci. Rep. 2018 ; 8:1-10.

15. Randall H, Valentin D, Crissy F, Vladislav V. Risks of Using Sterilization by Gamma Radiation: The Other Side of the Coin. Int J Med Sci 2018; 15: 274-9.

16. Stoch A, Jastrzębski W, Brozek A, Stoch J, Szaraniec J, Trybalska B et al. FTIR absorption-reflection study of biomimetic growth of phosphates on titanium implants. J. Mol. Struct. 2000; 555: 375-82.

17. Stefania C, Maria A, Ana M, Piergiorgio G, Elvira D. Surface Characterization of Electro-Assisted Titanium Implants A Multi-Technique Approach . J. Mater. 2020; 13: $1-30$.

18. Amini M, Alireza V, Zahra D and Mohammad H, Majles A. Effect of gamma irradiation on the structure characteristics and mass attenuation coefficient of $\mathrm{MgO}$ nanoparticles. Radiochim. Acta 2018 ; 106: 857 -64.
19. Amini M, Mohammad H, Majles A. Changes in structural and optical properties due to $\gamma$-irradiation of $\mathrm{MgO}$ nanoparticles Radiochim. Acta 2019 ;108:315-20.

20. Liu X, Zhou W, Wu Y, Cheng Y, Zheng Y. Effect of sterilization process on surface characteristics and biocompatibility of pure Mg and MgCa alloys. Mater. Sci. Eng. 2013 ;33: 4144-54.

21. Mohammed E, Bouazza T, Khalil E. A comparison of chitosan properties after extraction from shrimp shells by diluted and concentrated acids .Heliyon 2020; $6: 1-17$.

22. Carmen A, Rosestela P, Pedro S. Effects of gamma radiation in polymer blends, in composites with micro and nano fillers and in functionalized polyolefins. Rev. Latin Am. Metal. Mater.2010;30:3-27.

23. Abu Bakr E, Eman K, Salah M . Effect of gamma radiation on creep behavior, hardness and microstructure of Titanium dental material . J. Adv. Phys. 2017 ;13: 2347 3487.

24. Rodrigo N, Guillermina B, Esbaide A, Angel M. Effect of Ionizing Radiation on the Chemical Structure and the Physical Properties of Polycaprolactones of Different Molecular Weight . J. Polym. 2018 ;10: 1-17. 